\title{
Plant-based nutrient intake is positively associated with fat free mass index
}

\author{
E. Kelaiditi ${ }^{1}$, A. Jennings ${ }^{1}$, A. Cassidy ${ }^{1}$, A. Macgregor ${ }^{2}$, T. Spector ${ }^{2}$ and A. Welch ${ }^{1}$ \\ ${ }^{1}$ Department of Nutrition, Norwich Medical School, University of East Anglia, Norwich, Norfolk, NR4 7TJ and \\ ${ }^{2}$ Department of Twin Research \& Genetic Epidemiology, King's College London SEl 7EH, UK
}

Evidence suggests that a number of nutrients have been associated with muscle mass due to their anti-oxidant or anti-inflammatory properties (because oxidative stress and inflammation have been suggested as underlying mechanisms of sarcopenia) ${ }^{(1,2,3,4)}$. There are, however, limited studies on associations between habitual dietary intake and muscle mass ${ }^{(5)}$. The aim of this study was to investigate associations between a range of dietary plant-based nutrients, either involved in the human muscle biology or that act as antioxidants, and fat free mass index ${ }^{(6,7,8,9,10)}$.

A cross sectional study among 2570 women from the Twins UK adult twin registry, aged 18-79 yrs was conducted ${ }^{(11)}$. Ethical approval was obtained from the St. Thomas's Hospital Research Ethics committee and informed consent obtained from all subjects. Participants completed a food frequency questionnaire, which was used to calculate nutrient intake using values from the McCance and Widdowson food composition tables ${ }^{(12)}$. Body composition was measured using dual-energy X-ray absorptiometry. Fat Free Mass Index (FFMI - lean mass in $\mathrm{kg} / \mathrm{height}^{2}$ ) was calculated by quintiles of plant-based nutrients, after adjustment for age, physical activity, smoking, energy intake, and total body fat. Analysis was performed in STATA version 11.0 (STATA Corp, USA).

Mean age was 48.3 years and mean FFMI $15 \mathrm{~kg} / \mathrm{m}^{2}$. Differences for FFMI were significant for vitamin C, magnesium, potassium, and total carotene intakes between the top and bottom quintile with similar results for other carotenoids. Differences were not significant for vitamin $\mathrm{E}$ and selenium.

\begin{tabular}{lcccccr}
\hline & \multicolumn{4}{c}{ FFMI $\left(\mathrm{kg} / \mathrm{m}^{2}\right)^{l}$} \\
\cline { 2 - 3 } & \multicolumn{2}{c}{ Q1 $(n=514)$} & & Q5 $(n=514)$ & \\
\cline { 2 - 3 } Extreme quintiles of nutrient intakes & Mean & SE & & Mean & SE & $P$ for trend \\
\hline Vitamin C $(\mathrm{mg} / \mathrm{d})$ & 14.8 & 0.07 & & 15.3 & 0.07 & $<0.001$ \\
Vitamin E $(\mathrm{mg} / \mathrm{d})$ & 14.9 & 0.08 & & 15.0 & 0.08 & 0.875 \\
Magnesium $(\mathrm{mg} / \mathrm{d})$ & 14.8 & 0.09 & & 15.3 & 0.08 & 0.001 \\
Selenium $(\mu \mathrm{g} / \mathrm{d})$ & 15.0 & 0.08 & & 15.1 & 0.08 & 0.121 \\
Potassium $(\mathrm{mg} / \mathrm{d})$ & 14.8 & 0.09 & & 15.3 & 0.08 & $<0.001$ \\
Total carotene $(\mu \mathrm{g} / \mathrm{d})$ & 14.8 & 0.07 & & 15.1 & 0.07 & 0.003 \\
\hline
\end{tabular}

FFMI = Fat Free Mass Index $\left(\mathrm{kg} / \mathrm{m}^{2}\right)$. Values are means and Standard Errors in quintiles 1 and 5 of the nutrient intakes. ${ }^{I}$ Adjusted for age (yrs), physical activity (inactive, moderate, active), smoking history (never, former, current), energy intake (kcal/d), and total body fat $(\mathrm{kg})$.

In conclusion, we observed significant positive associations between plant-based nutrients and indexes of muscle mass in women. The greatest association was between vitamin C, magnesium, and potassium, and the FFMI and the difference between Q1 and Q5 was equivalent to $\approx 3 \%$ of the population mean for FFMI. The findings from this study suggest that, in women, consumption of plant-based nutrients, including vitamin $\mathrm{C}$, magnesium, potassium and carotenoids, may be important in maintaining fat free mass.

1. Robinson SM, Jameson KA, Batelaan SF et al. (2008) J Am Geriatr Soc 56, 84-90.

2. Laurentani F, Semba RD, Bandinelli S et al. (2008) J Gerontol Series A: Biological Sciences and Medical Sciences 63, $376-383$.

3. Dominguez LJ, Barbagallo M, Laurentani F (2006) Am J Clin Nutr 84, 419-426.

4. Dawson-Hughes B, Harris SS, Ceglia L (2008) Am J Clin Nutr 87, 662-5.

5. Scott D, Blizzard L, Fell J et al. (2010) J Am Geriatr Soc 58, 2129-2134.

6. Bischoff HA, Borchers M, Gudat F et al. (2001) Histochem J 33, 19-24.

7. Rock E, Astier C, Lab C et al. (1995) J Nutr 125, 1205-1210.

8. Fulle S, Protasi F, Di Tano G et al. (2004) Exp Gerontol 39, 17-24.

9. Frassetto L, Todd K, Morris R et al. (1998) Am J Clin Nutr 68, 576-583.

10. Young AJ, Phillip DM, Lowe GM. Carotenoids in Health and Disease. New York; 2004

11. Cassidy A, Skidmore P, Rimm EB et al. (2008) J Nutr 139, 353-358.

12. McCance and Widdowson's (2002) The Composition of Foods, Sixth summary edition. Food Standards Agency. Cambridge: Royal Society of Chemistry. 